\title{
Single Crystal Elastic Constants of TWIP Steel Determined From Nanoindentation
}

\author{
D. T. Pierce ${ }^{1}$, K. Nowag ${ }^{2}$, A. Montagne ${ }^{2}$, J. A. Jiménez ${ }^{3}$, J. E. Wittig ${ }^{1}$, R. Ghisleni ${ }^{2}$ \\ 1. Interdisciplinary Materials Science, Vanderbilt University, Nashville TN, USA \\ 2. Laboratory for Mechanics of Materials and Nanostructures, EMPA, Thun, Switzerland \\ 3. Centro Nacional de Investigaciones Metalurgicas (CENIM), Madrid, Spain
}

The stacking-fault energy (SFE) of austenitic Fe-Mn based twinning-induced plasticity (TWIP) steels is an important parameter that strongly influences their deformation mechanisms and mechanical properties [1]. Analysis of Shockley partial-dislocation pairs using weak-beam dark-field (WBDF) transmission electron microscopy (TEM) provides data for SFE measurements [1]. Applying anisotropic elastic dislocation theory can increase the accuracy of SFE measurements but necessitates the use of single crystal elastic stiffness constants $\mathrm{C}_{11}, \mathrm{C}_{12}$ and $\mathrm{C}_{44}$ [1]. Investigations of elastic anisotropy typically rely on single crystal material which is difficult to synthesize and not readily available. An alternative method uses nanoindentation in combination with orientation imaging microscopy (OIM) on polycrystalline specimens to determine the indentation modulus of specific crystallographic orientations. The objectives of this investigation are to a) develop a method to extract single crystal elastic constants from orientation specific indentation moduli and b) use this method to calculate elastic constants of an Fe-25Mn-3Al-3Si wt.\% alloy.

Specimens thermo-mechanically processed by hot and cold rolling were recrystallized at $1000^{\circ} \mathrm{C}$ for 30 minutes and polished with an automatic system. The final polishing step used a low load (10 N) with a suspension of $0.05 \mu \mathrm{m}$ colloidal silica for chemical-mechanical polishing (CMP) to ensure a flat surface with minimal deformation. Analysis of the surface topography with digital holographic microscopy (DHM), Figure 1, indicates a surface roughness, $S_{a}$, within grain boundaries of $\sim 3 \mathrm{~nm}$ (less than the 10 $\mathrm{nm}$ recommended by ASTM E2546). Figure 2 depicts a grain orientation map generated using a Zeiss scanning electron microscope (SEM) equipped with electron back-scatter diffraction (EBSD) orientation image mapping (OIM) capability. An Ubi indenter (Hysitron) equipped with a diamond Berkovich tip and working in load controlled mode indented grains with surface normals near $<111>,<110>$ and $<001>$. Indents within $10 \mu \mathrm{m}$ of grain and twin boundaries, as identified by SEM and shown in Figure 3, are excluded from the analysis. The orientation specific indentation modulus $\mathrm{M}_{(\mathrm{hkl})}$ is extracted from the unloading portion of load-displacement curves like that in Figure 4a using the Oliver-Pharr method [2].

Figure 4.b displays $\mathrm{M}_{(\mathrm{hkl})}$ for the $<111>,<110>$ and $<001>$ orientations. The $<111>$ orientation is $\sim 10 \%$ stiffer than the $<001>$ orientation. The anisotropy factor, $A=2 C_{44} /\left(C_{11}-C_{12}\right)$, is calculated from the ratio of $\mathrm{M}_{(111)} / \mathrm{M}_{(001)}$ by the relationship developed in [3]. A second relationship between the polycrystalline shear modulus and $\mathrm{C}_{11}, \mathrm{C}_{12}$ and $\mathrm{C}_{44}$ is given in [4]. A materials bulk modulus $\mathrm{K}$ may be related to the single crystal elastic constants by $\mathrm{K}=\left(\mathrm{C}_{11}+2 \mathrm{C}_{12}\right) / 3$ [4]. By performing an iterative calculation procedure, the system of three independent equations yields values of $\mathrm{C}_{11}, \mathrm{C}_{12}$ and $\mathrm{C}_{44}$ of $174 \pm 7,85 \pm 3$, and $99 \pm 4$ $\mathrm{GPa}$ respectively and an anisotropy factor of $2.2 \pm 0.2$. Interestingly, the calculated anisotropy for this alloy in the paramagnetic state is significantly lower than that of 3.9 for a similar Fe-40Mn at.\% alloy in the antiferromagnetic state [5], suggesting magnetic ordering may play a role in the elastic anisotropy of TWIP steels. To test the accuracy of this method, monocrystal elastic constants were calculated from indentation moduli available for $\mathrm{W}, \mathrm{Al}, \mathrm{Cu}$, and $\beta$-brass [3]. The calculated elastic constants, $\mathrm{C}_{11}, \mathrm{C}_{12}$ and $\mathrm{C}_{44}$, display good agreement with the literature values, differing by a standard deviation of $\sim 4 \%$. These values represent some of the first experimental single crystal elastic constants for TWIP steels and will be used to increase the accuracy of SFE measurements in future investigations [6]. 


\section{References}

[1] D. T. Pierce et al., Scripta Mat. 66 (2012) p. 753.

[2] W. C. Oliver, G. M. Pharr, J. Mater. Sci. 76 (1992) p. 1564.

[3] J. J. Vlassak, W. D. Nix, J. Mech. Phys. Solids 42 (1994) p. 1223.

[4] H. M. Ledbetter, Phys. Stat. Sol. (a) 85 (1984) p. 89.

[5] M. Cankurtaran et al., Phys. Rev. B 47 (1993) p. 3161.

[6] Financial support from the NSF DMR 0805295 and the DFG SFB 761 is gratefully acknowledged.

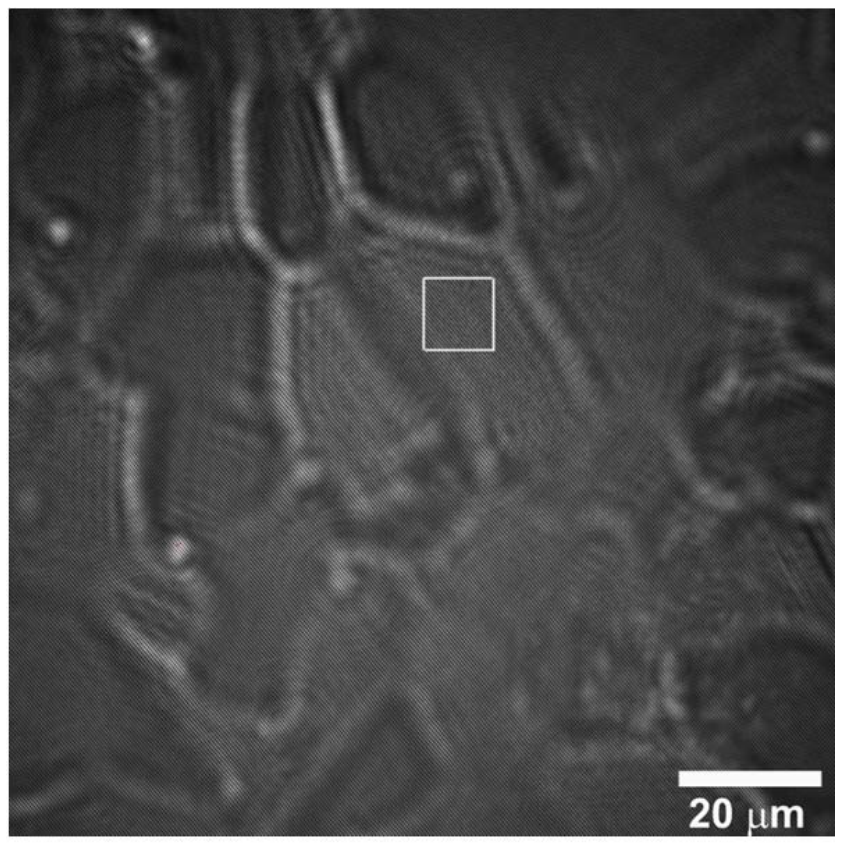

Fig. 1. Digital hologram of specimen surface. Surface roughness calculated from boxed area.

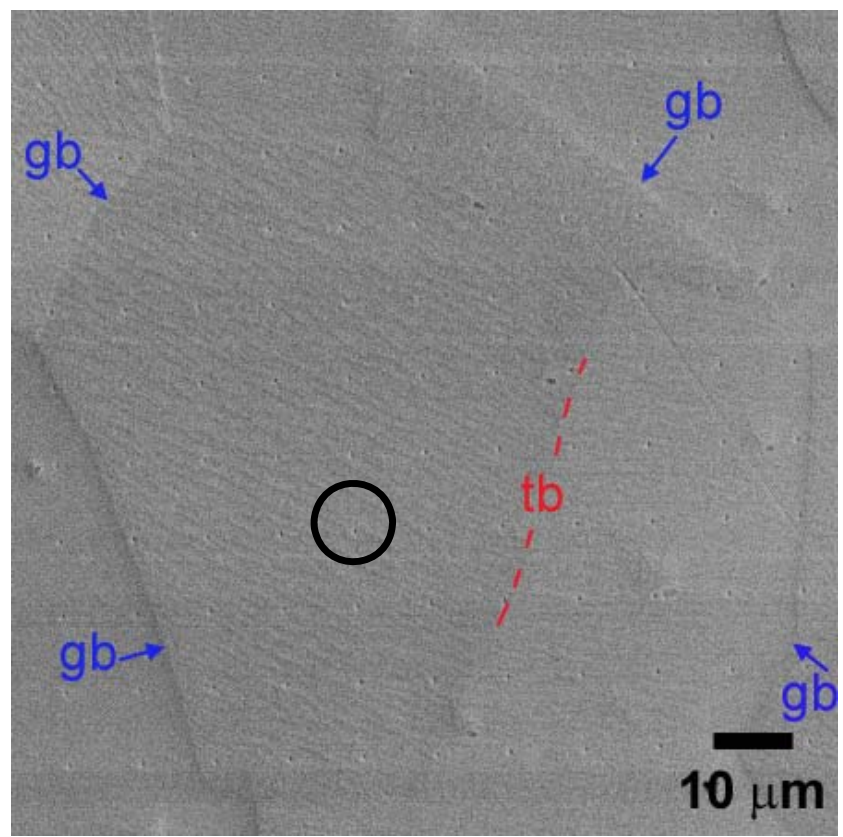

Fig. 3. SEM image of indented grain circled in Fig. 2. Grain and twin boundaries (gb) and (tb).

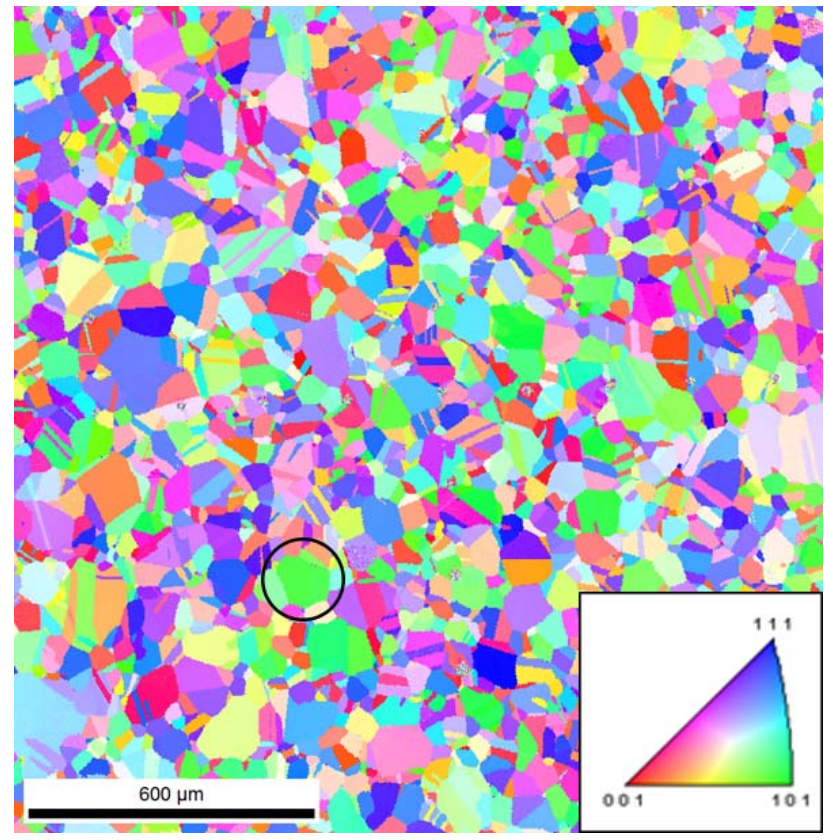

Fig. 2. Grain orientation map of Fe-25Mn-3Al3 Si steel.

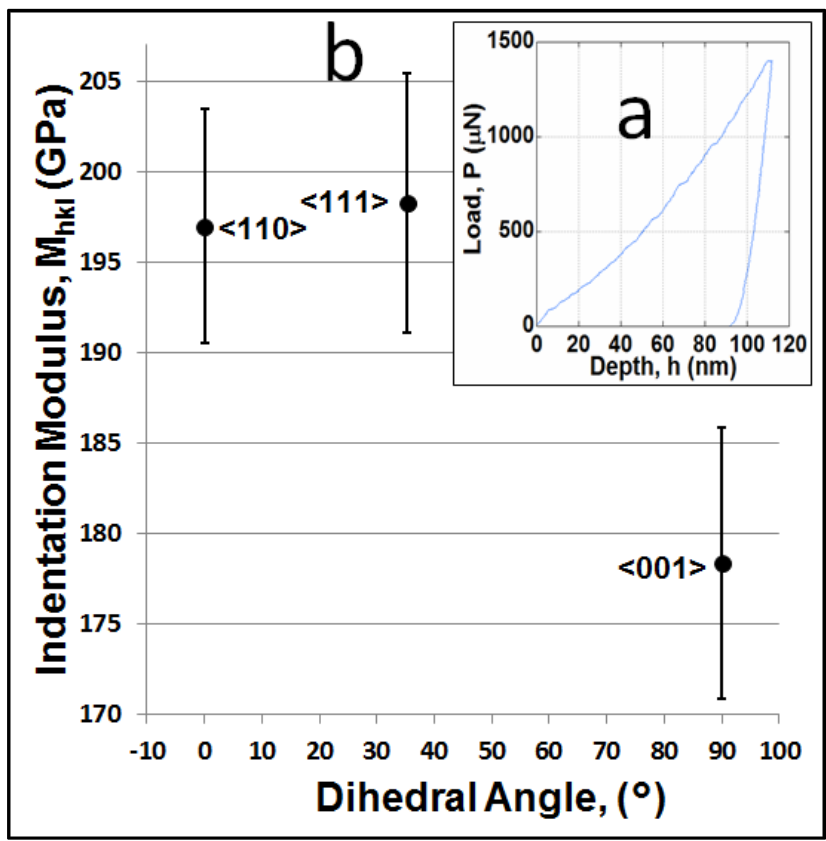

Fig. 4. (a) Load vs. depth curve of circled indent in Fig. 3 and (b) $\mathrm{M}_{(\mathrm{hkl})}$ vs. dihedral angle. 